\title{
¿Existen sesgos de género que se reproducen y perpetúan en la enseñanza actual de la biotecnología? Estudio de caso: Aula de Recuperación y Purificación de Proteínas de la Licenciatura en Biotecnología de la Universidad Nacional de Quilmes.
}

\section{Are gender biases reproduced in current biotechnology learning? Study case: Classroom of "Protein recovery and purification" of the Bachelor of Biotechnology at Quilmes National University}

ARTÍCULO

\author{
María Laura Carbajal \\ Universidad Nacional de Quilmes, Instituto de Estudios Sociales de la Ciencia y la \\ Tecnología. Contacto: mlcarbajal@unq.edu.ar
}

Recibido: agosto de 2021

Aceptado: octubre de 2021

\section{Resumen}

A partir de producciones escritas de dos cohortes, y mediante el análisis discursivo cualitativo, se pretende visibilizar y diagnosticar en qué medida el profesorado y el estudiantado de esta asignatura mantienen concepciones, supuestos, asunciones y valores sesgados acerca del género. Se asume la hipótesis de que existen sesgos de género en las ciencias (investigaciones y teorías) y que se transmiten en la educación y formación científica, perpetuándose. En un primer estudio, se propone analizar con perspectiva de género el material didáctico generado por el cuerpo docente, desde el punto de vista del lenguaje (sexuado o inclusive) y los modelos de ciencia que se transmiten en las representaciones semióticas. Luego, se propone analizar, por medio de dimensiones psicosociales, la producción escrita de las personas estudiantes (en particular las reflexiones sobre la práctica), en la búsqueda de creencias, expectativas y valoraciones. Y por último, también en las reflexiones sobre la práctica, se busca comparar las autopercepciones sobre el rendimiento académico. A partir del análisis cualitativo propuesto, se detectaron sesgos de género en el aula de "Recuperación y Purificación de Proteínas", de la carrera de biotecnología de la UNQ, validándose la hipótesis propuesta. Por lo cual, se proponen 
diferentes acciones para promover la equidad de género a través de la comunicación en el aula.*

Palabras clave: Educación científica, ciencia, biotecnología, perspectiva de género, estereotipos de género.

\section{Abstract}

The aim of this work is to make visible and diagnose to what extent the teachers and students of this subject maintain gender biased conceptions, assumptions and values. The hypothesis assumed it that there are gender biases in the sciences and that they are transmitted and perpetuated in scientific education. In goal to achieve it, written productions of two cohorts were analyzed it through qualitative discursive analysis. Then, it was proposed to analyze, by means of psychosocial dimensions, the written production of the students (in particular the reflections on the practice), in the search for beliefs and expectations.

In addition, the didactic material generated by the teachers, were also analyzed it from a gender perspective. It was focus on the point of view of language (sexed or inclusive) and on which model of science was transmitted it in semiotic representations. Finally, on student's reflections on own practice, it seek to compare self-perceptions on academic performance. Based on the proposed qualitative analysis, gender biases were detected it at the "Protein Recovery and Purification" classroom of the UNQ biotechnology career, validating the proposed hypothesis. Therefore, different actions were proposed to promote gender equality through communication in the classroom.

Keywords: Scientific Education, Science, Biotechnology, Gender perspective, Gender stereotypes.

\section{Introducción}

\section{Modelo de ciencia predominante y surgimiento de otras concepciones}

La representación actual predominante de ciencia posee una visión androcéntrica y tradicional. Donde se entiende a la ciencia como una actividad objetiva, racional, inductiva, neutra y analítica. Sin embargo, resulta en una visión sesgada y distorsionada ya que se ha limitado e invisibilizado la participación, la educación científica, la producción y el pensamiento de las mujeres (González y Fernández, 2016; Camacho 2018). En la presentación de su documento, Corbalán y Pérez Scalzi (2019) mencionan:

El androcentrismo consiste en una visión del mundo que tiene como centro o eje principal a los hombres, sus actividades y los valores asociados a la masculinidad como parámetro de lo humano. La visión "androcéntrica" segmenta a mujeres y 
hombres y refuerza estereotipos de unas y otros según los papeles (roles) que deben cumplir en diversos ámbitos de la vida pública y privada. El sexismo se refiere a todas aquellas prácticas y actitudes que promueven el trato diferenciado de las personas en razón de su sexo biológico, del cual se asumen características y comportamientos que se espera, las mujeres y los hombres, actúen cotidianamente. Las prácticas sexistas afectan principalmente a las mujeres dada la vigencia de creencias culturales que las consideran inferiores o desiguales a los hombres por naturaleza (p. 3).

Según Suárez Tomé y Bello (2017), desde el enfoque de la historia de la filosofía feminista se expone una

ciencia con características androcéntricas, producto de la humanidad. Donde históricamente se ha representado a la mujer como un ser irracional y dominado por sus emociones. Las capacidades de racionalidad, abstracción y universalización no le pertenecen por naturaleza. En las áreas de producción de conocimiento la figura del varón hegemónico (cisexual, heterosexual, blanco, capacitado, propietario) ha sido dominante y la única tradicionalmente legítima. La figura de mujer no se percibe como legítima productora de conocimiento (Suárez Tomé \& Bello, 2017, 25 de febrero).

Los estudios de ciencia, tecnología y género encaran estas problemáticas desde dos enfoques distintos: uno se ocupa de la situación de la mujer dentro de la ciencia y la tecnología; y el otro de la ciencia y la tecnología en el feminismo. El estudio de la situación de olvido o invisibilización de la mujer en la ciencia puede encararse desde el marco histórico-sociológico y desde los estudios empíricos sobre los usos sexistas de la ciencia. La historia de la ciencia desde un enfoque de género permite analizar críticamente las relaciones entre ciencia-tecnología y género-sociedad a lo largo de la historia y en el presente. A partir de los años 60 se abre un nuevo campo de investigación sobre las relaciones entre la ciencia, la tecnología y la sociedad ante la pregunta "¿Por qué tan pocas?". Desde entonces, el análisis de género ha contribuido a las transformaciones en la concepción de la ciencia y la tecnología (González y Fernández, 2016). Sobre la ciencia en el feminismo, Marta I. González García y Eulalia Pérez Sedeño (2002) realizan una clasificación de las corrientes más significativas. Si bien dentro de las teorías feministas surgen tensiones fundamentales, apuntan a reapropiarse de la filosofía tradicional y generar conocimiento enriquecido en perspectivas. Dan lugar a diversas posturas epistemológicas desde una perspectiva feminista, sobre el papel del sujeto cognoscente o la posibilidad y justificación del conocimiento. Por lo cual, se enfocan en el análisis de los sesgos sexistas y androcéntricos presentes en los contenidos y prácticas científico-tecnológicas (Centro REDES, 2018; Cuenca Sánchez, 2018).

Las estrategias para promover la incorporación de las mujeres al estudio de la ciencia se pueden proponer a través de la investigación educativa y los programas de inclusión.

\section{Sobre la problemática de la mujer en la ciencia}

La UNESCO ha realizado varios informes y estudios analizando los orígenes de la problemática de por qué las niñas y adolescentes eligen determinadas trayectorias 
educativas (Bonder, 2017). Desde la infancia, se busca promover que las mujeres estudien y se desarrollen en las denominadas STEM\&A (del inglés Science, Technology, Engineering, Mathematics and Arts) o CTIM\&A (Ciencia, Tecnología, Ingeniería, Matemáticas y Arte). Las mujeres constituyen sólo un $28 \%$ de las personas investigadoras a nivel global. La Argentina se encuentra cerca de la paridad. Sin embargo, la situación de la mujer en el sistema de ciencia y Tecnología argentino no escapa a las tendencias mundiales (Lafuente Duarte et al., 2020). En cuanto a las trayectorias educativas de las mujeres, se diagnostica que las elecciones de campos de estudio se encuentran correlacionadas con roles y estereotipos de género (D'Onofrio y Tignino, 2018). Se concentran en las ciencias sociales y en las ciencias médicas y de la salud, y permanecen sub-representadas en las ingenierías y tecnologías y en las ciencias naturales y exactas. En cuanto al desarrollo profesional, ven limitado el acceso a posiciones jerárquicas, hay una baja representación en los puestos de mayor responsabilidad e incidencia en la toma de decisiones de los ámbitos académicos y científico tecnológico ("techo de cristal"), y a esto se suma el ejercicio del rol estereotipado de tareas de cuidado ("piso pegajoso" y "tubería agujereada"), el prejuicio en contra de reconocer los logros de las mujeres científicas (el "efecto Matilda"), la existencia de un único modelo femenino a seguir ("efecto Curie") (Franchi et al, 2016; Camacho, 2018; Lafuente Duarte et al, 2020).

\section{Patrones de género en la Enseñanza de las ciencias}

La problemática de género y ciencia tiene especial repercusión en la enseñanza de la ciencia, especialmente en los niveles primario y medio de educación. Los roles de género tradicionales y los estereotipos sexistas son considerados factores que inciden sobre la brecha de género en el rendimiento educativo en ciencias (biología, química, física, matemática), en la generación de actitudes menos favorables, y en el desinterés por la elección de carreras científico técnicas (Manassero y Vázquez, 2003a). Teniendo como consecuencia la infrarrepresentación de las mujeres en la educación superior en las áreas STEM\&A. Los indicadores de rendimiento y resultados educativos europeos fueron estudiados por PISA (Programme for International Student Assessment) y TIMSS (Trends in International Mathematics and Science Study). Estos estudios muestran que el auto concepto (estima) y la confianza en sus capacidades científicas para las niñas y las jóvenes, son inferiores a la media. Abordar estos factores de desigualdad por medio de estrategias y políticas de género en todos los sistemas y niveles educativos repercutiría no sólo en la enseñanza de la ciencia sino también sobre las segregaciones vertical y horizontal existentes en los sistemas científicos, ya que se encuentran correlacionadas. La segregación horizontal refiere a la elección de estudios superiores, con la consecuente masculinización/feminización de carreras y áreas profesionales. La segregación vertical se 
refiere a las oportunidades que se ofrecen en los niveles de educación superior y de la formación profesional, y se traduce en infrarrepresentación de las mujeres. Algunas respuestas o estrategias específicas propuestas para promover la igualdad en la enseñanza de la ciencia son: (i) la evaluación de libros de texto y material didáctico, recomendando lo establecido por las políticas de igualdad (ii) incluir la perspectiva de género en la formación del profesorado; (iii) la promoción de la educación científica (Pastor Antequera y García Fernández, 2011).

\section{Valores y sesgos de género en el conocimiento científico y en su transmisión}

Los sesgos de género son culturales y como constructo social, atraviesan tanto el cuerpo de conocimiento cotidiano como del conocimiento científico. De esta manera, se encuentran presentes en las representaciones sociales de ambas visiones del mundo. El estereotipo de género es una construcción social tan fuerte que llega a creerse que es algo "natural e incuestionable". Sin embargo, está elaborado sobre prejuicios, actitudes y creencias aplicadas a todas las personas en general. Se torna negativo cuando impide el desarrollo de las personas, y establece jerarquías de subordinación de las mujeres respecto de los varones (y de algunos varones entre sí), negando el ejercicio pleno de los derechos. Los roles de género son aquellas expectativas sociales creadas en torno al comportamiento masculino y femenino y representan lo que se espera sea el accionar de los varones y las mujeres. Contienen auto-conceptos y características psicológicas de acuerdo con dicotomías que los separan y los posicionan como opuestos. Por ejemplo y en general, para el varón se asignan socioculturalmente atributos de fortaleza, actividad, control, racionalidad, valores de mayor competitividad, liderazgo, más iniciativa, menos cuidadosos, así como roles de proveedor asociado al espacio público. En cambio, para la mujer se asignan atributos de sensibilidad, pasividad (esperan indicaciones y ordenes), emotividad, irracionales, valores de creatividad, más detallistas, se la asocia con la naturaleza (en oposición al raciocinio), y roles de maternidad y cuidado asociados con el espacio privado. Para los hombres también se adjudican valores como lealtad, justicia, sabiduría, confianza mientras que a la mujer se asignan fidelidad, generosidad, cordialidad, fragilidad, coquetería (Mata Coca, 2002). Estos son prejuicios y estereotipos culturales con sesgo de género y conforman representaciones sociales e identitarias (Flores Palacio, 2012; Vázquez-Cupeiro, 2015; SITEAL, 2019).

El grupo de trabajo de Carmen Solís-Espallargas (2018) realizó un estudio preliminar en la Universidad de la Laguna (España) sobre valores y sesgos en el conocimiento científico y en su transmisión. Como primeras conclusiones obtuvieron que en los profesorados de ciencia objeto de estudio aparecen sesgos de género respecto a las estudiantes en la enseñanza de la ciencia y las tecnologías. Observaron que están 
relacionados con las capacidades cognitivas, las destrezas, las actitudes y las interacciones de las estudiantes y los estudiantes en el aprendizaje de la ciencia y las tecnologías. Estas valoraciones halladas contribuyen a fomentar los estereotipos de género junto a otros factores como la imagen masculina dominante de la ciencia que se refleja en el currículo de ciencias y en los libros de texto. Ocupando un lugar importante en la construcción de la identidad y la subjetividad en las mujeres dedicadas a las tareas científicas.

Tanto los libros de texto como las producciones didácticas extienden los conocimientos básicos al estudiantado, dando forma a las impresiones sobre la naturaleza del trabajo científico, sobre quién se convierte en científico/a, o qué tipo de problemas tienen para resolver quienes son especialistas. Pueden incorporar estereotipos que perpetúan los supuestos de género y producen una ciencia poco sólida (Schiebinger et al, 2011-2020). Los roles, la división sexual del trabajo así como los comportamientos y sentimientos suelen ser valorados de acuerdo al género (González Ramírez, 2008).

En la transmisión de modelos y valores en los libros de texto de enseñanza de la ciencia, se han encontrado estereotipos de género que promueven el modelo dominante de un mundo masculino (Manassero y Vázquez, 2002). El Proyecto de Innovación en Género de la Universidad de Stanford, luego de una revisión de libros de texto de enseñanza de la biología, propone innovaciones sobre el lenguaje y las representaciones visuales. Argumenta que "el lenguaje (elección de palabras, metáforas, analogías y prácticas de denominación elegidas para explicar conceptos científicos) y las representaciones visuales (imágenes, tablas y gráficos elegidos para ilustrar conceptos científicos) tienen el poder de dar forma a la práctica científica: las preguntas formuladas, los resultados obtenidos, y las interpretaciones hechas" (Schiebinger et al, 2011-2020).

Manassero y Vázquez (2003b) proponen que brindar ejemplos desde el enfoque ciencia-tecnología y sociedad (CTS) en vez del enfoque positivista podría dar una visión de la ciencia más relacionada con la vida diaria, con las realizaciones tecnológicas y sus implicancias sociales.

En los procesos de socialización actuales, el sesgo de género se sigue transmitiendo y se perpetúa en todos los niveles educativos. De esta manera, se continúa legitimando la dominación de lo masculino sobre lo femenino en todos los contextos. La equidad de género se ve afectada entonces por los constructos sociales, las representaciones mentales y las formas de ejercer el poder de acuerdo a los usos y costumbres de cada cultura. Al explorar las representaciones mentales en relación al género, manifestadas a través del lenguaje de estudiantes de educación superior, se han podido detectar e identificar estereotipos y roles de género subyacentes (Winfield, 2017).

\section{El lenguaje sexista en la educación}


En el entorno educativo en general y en la educación en ciencias en particular, así como en los tres niveles educativos, los patrones sexistas pueden transmitirse a través del lenguaje cotidiano y del lenguaje científico (escrito, verbal o iconográfico). A través del uso sexista del lenguaje se asientan y perpetúan estereotipos de género, se oculta y desvaloriza a las mujeres, y se contribuye a una visión sesgada del mundo (Via Ampuero, 2008). Una de las formas del lenguaje sexista es que se recurre al masculino genérico para nombrar al colectivo mixto, lo femenino y lo masculino. Esto contribuye a la invisibilización, ya que no se hace referencia explícita a la presencia de las mujeres en el valor del conjunto mismo. El androcentrismo como forma de mirar el mundo, donde el varón es el referente y la medida de las cosas, siendo que la existencia de la mujer se encuentra subordinada y es dependiente de esta figura. Se atribuyen características distintivas y se asignan valores, capacidades y roles diferentes -también llamados estereotipos sexuales de comportamiento o de carácter- a mujeres y hombres en función de su sexo biológico. En algunos casos, esta dualidad aparente, lleva a que un mismo concepto tenga acepciones masculinas y femeninas, pudiendo llevar a desvalorizaciones y descalificaciones.

Este lenguaje sexista, donde se abusa del genérico masculino y la presencia femenina es escasa, nula o estereotipada, está arraigado en el imaginario social y en la conducta cotidiana. Justamente, es en el ámbito educativo, donde se puede resignificar el uso del lenguaje (y del pensamiento) para transmitir valores no sexistas. Lo cual podría contribuir a producir cambios significativos en lo social. Por ejemplo, pensar y repensar lo que se dice, se comunica y se transmite, ya sea desde la oralidad como desde las representaciones semióticas de los materiales didácticos y producciones docentes. Las principales reglas para un lenguaje inclusivo e igualitarios involucran: (i) evitar expresiones donde se incluyan formas de masculino genérico, pares aparentes o androcentrismo excluyente; (ii) evitar alusiones a modelos masculinos frente a femeninos estereotipados, en función de lo que son, lo que hacen o como se relacionan, (iii) sugerir ejemplos tanto en femenino como en masculino, evitando asociar a modelos y valores estereotipados (Velasco et al, 2009).

\section{Contexto áulico}

La asignatura "Recuperación y Purificación de Proteínas" (RPP) pertenece al plan de estudios de la Licenciatura en Biotecnología de la Universidad Nacional de Quilmes (UNQ), Argentina. Se encuadra dentro del área de conocimiento de la Biotecnología Industrial y de los Bioprocesos. El objetivo general de RPP es que el estudiantado comprenda las diferentes etapas de recuperación y purificación que involucran la obtención de un producto biotecnológico (downstream). Para ello, se realiza el análisis y la comparación de las diferentes tecnologías de cada operación unitaria, para introducir en la problemática de la escala piloto-industrial. Se presentan contenidos de carácter técnico y tecnológico. Cuenta 
modalidad de cursada presencial y bimodal (desde 2018), con carácter teórico-experimental. Durante el año 2020, toda la actividad áulica fue desarrollada en el entorno virtual debido al Aislamiento Social y Preventivo Obligatorio (ASPO) a causa de la pandemia de Covid-19.

Se hace énfasis en la experimentación como factor fundamental para favorecer un aprendizaje significativo. Una gran proporción de la carga horaria de RPP (unas $3 / 4$ partes) es destinada a actividades experimentales de laboratorio, seminarios de discusión y resolución de problemas (Problem-Based Learning). Esta asignatura la cursan estudiantes de tercer y/o cuarto año de la carrera. En consecuencia es una población con características heterogéneas en cuanto a niveles de desarrollo y competencias. Cabe aclarar que la Licenciatura en Biotecnología de la Universidad Nacional de Quilmes (UNQ) es una carrera feminizada (aproximadamente $65 \%$ mujeres) ${ }^{1}$.

Se contemplan distintos instrumentos de evaluación (diagnóstica, de proceso y final o integradora). Dentro de estos instrumentos se incluyen producciones como: informes de trabajos prácticos de elaboración grupal; coevaluaciones mediante la técnica de retroalimentación por pirámide; y, la reflexión sobre la práctica (auto-evaluación) mediante portafolios de carácter individual.

\section{Propuesta para el estudio de caso}

Se propone entonces detectar valores y sesgos de género que operan en el contexto de la educación científica en el Aula de RPP a través del análisis del lenguaje de las producciones de docentes y estudiantes de dos cuatrimestres consecutivos (tres comisiones). Se elige esta asignatura no sólo por las características científico-tecnológicas de la misma descritas en la sección previa de contexto áulico sino también porque existe la factibilidad de implementar acciones de intervención pedagógica.

Se asume la hipótesis de que existen sesgos de género en las ciencias (investigaciones y teorías) y que se transmiten en la educación y formación científica perpetuándose:

- En los materiales didácticos elaborados se transmiten estereotipos a través del lenguaje y las imágenes.

- Se mantienen valores y creencias sexistas (expectativas, actitudes y prácticas) con efectos sobre la propia valoración y autopercepción que las estudiantes tienen de sus capacidades y posibilidades en la formación científica y en su futuro profesional.

- Existen sesgos de género en la formación científica y tecnológica en la enseñanza superior.

\footnotetext{
${ }^{1}$ Información otorgada por la Dirección de la carrera de Lic. en Biotecnología, UNQ. Enero 2019.
} 


\section{Objetivos}

Diagnosticar, detectar y visibilizar los valores y sesgos de género que operan en el contexto de la educación científica en el Aula de RPP mediante el análisis discursivo.

\section{Metodología}

Este objetivo se investiga y focaliza sobre las producciones escritas tanto de docentes como de estudiantes. Busca visibilizar en qué medida el plantel docente y el estudiantado mantienen concepciones, supuestos, asunciones y valores sesgados acerca del género. Se presenta un análisis cualitativo.

En el primer Estudio, se propone analizar desde el discurso y representaciones gráficas, los materiales didácticos como el programa (currícula y contenidos), cronograma (organización), clases teóricas (presentaciones multimedia), guías de laboratorio y de resolución de problemas, guías para la elaboración de informes y para la elaboración de autoevaluaciones, bibliografía de referencia, y el diseño de evaluaciones escritas. Se analizan con perspectiva de género las producciones docentes, tanto el tipo de lenguaje utilizado (si se utiliza, parcialmente o no, el lenguaje no sexista) como que modelos se transmiten en las representaciones semióticas.

En el Estudio 2 por otra parte, se analiza la producción escrita de informes grupales y auto-evaluaciones (reflexiones sobre la práctica). Se busca evidenciar creencias, expectativas y valoraciones tanto en las dinámicas individuales como grupales desde el punto de vista de las subjetividades por medio de dimensiones psicosociales (afectivas, emocionales, toma de decisiones, auto-concepto, relaciones entre pares, etc.) (Colás Bravo y Villaciervos Moreno, 2007). Incluyendo tanto prejuicios y sus componentes valorativos, cognitivos y emocionales, así como estereotipos acerca de los roles sociales de mujeres y varones y los sentimientos o sensaciones que generan (como confianza y seguridad). En el estudio 3, se comparan las autopercepciones sobre el rendimiento académico.

Finalmente, proponer acciones para promover la equidad de género a través de la comunicación en el aula de RPP.

\section{Universo de estudio}

Se decidió analizar las producciones docentes y de estudiantes del aula RPP de comisiones de dos cuatrimestres consecutivos.

Comisión de RPP del segundo cuatrimestre del 2019: La cantidad de personas inscriptas fue de 36 estudiantes, siendo el $72 \%$ mujeres. Para las actividades de laboratorio y de elaboración de informes, el gran grupo se dividió en 8 grupos más pequeños. Hubo tres 
casos de abandono antes del primer examen, dos varones (G5 y G6) y una mujer (G1).

Quedando conformados de la siguiente manera hasta el final de la cursada:

\begin{tabular}{|l|c|c|c|c|c|c|c|c|}
\hline Composición & $\begin{array}{c}\text { G1 } \\
\text { (fem) }\end{array}$ & $\begin{array}{c}\text { G2 } \\
\text { (mixto) }\end{array}$ & $\begin{array}{c}\text { G3 } \\
\text { (mixto) }\end{array}$ & $\begin{array}{c}\text { G4 } \\
\text { (fem) }\end{array}$ & $\begin{array}{c}\text { G5 } \\
\text { (mixto) }\end{array}$ & $\begin{array}{c}\text { G6 } \\
\text { (masc) }\end{array}$ & $\begin{array}{c}\text { G7 } \\
\text { (fem) }\end{array}$ & $\begin{array}{c}\text { G8 } \\
\text { (mixto) }\end{array}$ \\
\hline Mujeres & 4 & 4 & 3 & 4 & 3 & - & 4 & 3 \\
\hline Varones & - & 1 & 1 & - & 1 & 3 & - & 2 \\
\hline Total & 4 & 5 & 4 & 4 & 4 & 3 & 4 & 5 \\
\hline
\end{tabular}

Dado que fue un cuatrimestre atípico por la cantidad de estudiantes que se inscribieron, hubo cuatro docentes con roles diferenciados para llevar a cabo el normal desenvolvimiento de las clases: un docente titular, quien se ocupó de las clases teóricas; una docente adjunta, quien se ocupó de las clases de seminarios de resolución de problemas y trabajos prácticos computacionales; una docente instructora y un docente instructor quienes estuvieron a cargo de las prácticas experimentales en el laboratorio. Todo el cuerpo docente participa de la evaluación del curso. El dictado fue presencial.

Comisiones del Primer cuatrimestre del 2020: Este también fue un cuatrimestre atípico debido al aislamiento social preventivo obligatorio (ASPO) por Pandemia COVID, y ambas cursadas (presencial y bimodal) se desarrollaron virtualmente y en colaboración. El cuerpo docente de la comisión matutina es femenino (dos profesoras) mientras que la nocturna es mixto (un profesor y una profesora). Sin embargo, se trabajó en conjunto para optimizar recursos. A la fecha de cierre de las asignaturas, las actividades experimentales grupales presenciales no han podido realizarse.

- Comisión matutina (M): 10 personas estudiantes inscriptas (3 varones, 7 mujeres). Se presentó un caso de abandono (una mujer) antes del primer parcial.

- Comisión nocturna (N): 14 personas estudiantes inscriptas (8 varones; 6 mujeres).

Para las actividades de análisis de datos y elaboración de informes, el gran grupo se dividió en grupos más pequeños con la siguiente composición (ver Tabla 2).

Tabla 2: Composición de grupos (G) en comisiones Matutina (M) y Nocturna (N) 2020.

\begin{tabular}{|l|c|c|c|c|c|c|c|c|}
\hline $\begin{array}{l}\text { Composició } \\
\mathrm{n}\end{array}$ & $\begin{array}{c}\mathrm{G} 1 \mathrm{M} \\
\text { (mixto) }\end{array}$ & $\begin{array}{c}\mathrm{G} 2 \mathrm{M} \\
\text { (mixto) }\end{array}$ & $\begin{array}{c}\mathrm{G} 3 \mathrm{M} \\
\text { (mixto) }\end{array}$ & $\begin{array}{c}\mathrm{G} 4 \mathrm{M} \\
\text { (fem) }\end{array}$ & $\begin{array}{c}\mathrm{G} 1 \mathrm{~N} \\
\text { (mixto) }\end{array}$ & $\begin{array}{c}\mathrm{G} 2 \mathrm{~N} \\
\text { (mixto) }\end{array}$ & $\begin{array}{c}\mathrm{G} 3 \mathrm{~N} \\
\text { (mixto) }\end{array}$ & $\begin{array}{c}\mathrm{G} 4 \mathrm{~N} \\
\text { (masc) }\end{array}$ \\
\hline Mujeres & 1 & 2 & 1 & 2 & 3 & 1 & 2 & - \\
\hline Varones & 1 & 1 & 1 & - & 2 & 2 & 1 & 3 \\
\hline Total & 2 & 3 & 2 & 2 & 5 & 3 & 3 & 3 \\
\hline
\end{tabular}

\section{Resultados y discusión}

Estudio 1: análisis del tipo de lenguaje y representaciones semióticas en las producciones del profesorado 
Para el contexto educativo del Aula de Recuperación y Purificación de Proteínas (RPP) se analizó el lenguaje científico -retórica e imágenes ilustrativas- en las producciones del plantel docente. Cabe aclarar que al ser una asignatura donde se presentan contenidos de carácter técnico y tecnológico, de nivel intermedio en grado de avance, el lenguaje científico es de uso habitual. Este lenguaje científico es representativo de la cultura científica y del modelo de ciencia predominante.

El enfoque implementado fue desde la perspectiva de género. Se analizó si se utiliza, parcialmente o no, el lenguaje no sexista y qué modelo de ciencia se transmite en las representaciones semióticas (modelos estereotipados, masculinos frente a femeninos).

En cuanto al material de apoyo para las clases teóricas (de carácter expositivo con power point) se encontró que se utiliza un lenguaje técnico y en general son de tenor descriptivo. Se usan enunciados (textos), esquemas, figuras y enumeraciones. En cuanto a organización y exposición de los conceptos, en general se realiza una historicidad temática introductoria. En esta historicidad se mencionan los hitos y personas destacadas en el desarrollo de las técnicas y/o tecnologías descritas. En todos los casos, estos resultan ser hombres. No hay mención a mujeres. Respecto de las fotografías, se notó que en general se muestran los equipamientos. En un único caso se incluyó una persona y resultó ser... un varón. Implicando el modelo predominante de ciencia androcéntrica y representando al rol masculino en el quehacer experimental científico.

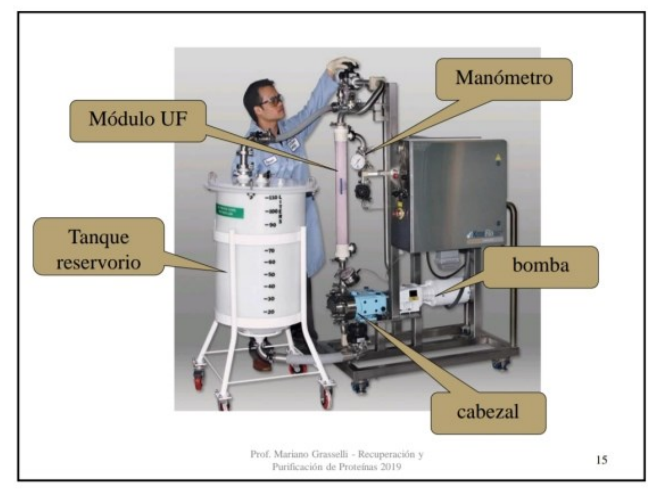

Por lo cual, tal como mencionan Camacho (2018) y Velasco et al. (2009) para evitar seguir reproduciendo estereotipos en la enseñanza de las ciencias, es recomendable incluir representaciones semióticas neutras sin sesgos de género. Tales como fotografías de equipamientos sin personas o en caso de haber personas que no sea sólo varón. También recurrir a la historia feminista de la ciencia para comenzar a visibilizar trayectorias femeninas.

En cuanto al lenguaje sexista, se encuentra presente ya que se detectó la utilización del masculino genérico "Alumnos", el cual fácilmente puede reemplazarse por el genérico "personas estudiantes", estudiantado o alumnado, cuerpo estudiantil, personas que estudian. Estas son alternativas que incluyen todos los géneros y son de carácter neutro, característica del lenguaje no sexista o inclusivo. Como alternativa binaria también podría 
ser "las alumnas y los alumnos", visibilizando de esta manera a las mujeres. Lo mismo cuando refiere a profesores, siendo la alternativa el uso de profesorado, cuerpo docente, plantel docente, o personas docentes/profesoras. También se detectó la referencia a "los autores" de determinado trabajo científico (pudiendo reemplazarse por autoría, por ejemplo) y a "Horas hombre" en vez de "horas de trabajo". Sería entonces recomendable evitar expresiones donde se incluyan formas de masculino genérico, pares aparentes o androcentrismo excluyente.

En la tabla 1 se expone el análisis integral y resumido de las producciones docentes para el Aula de RPP. Corresponde al material del segundo cuatrimestre del 2019, ya que para el 2020 fueron modificadas siguiendo las recomendaciones.

Tabla 1: Análisis sobre las Producciones del plantel docente

\begin{tabular}{|c|c|c|c|c|}
\hline $\begin{array}{l}\text { Material } \\
\text { Didáctico }\end{array}$ & Descripción & $\begin{array}{l}\text { Sesgo de género } \\
\text { detectado }\end{array}$ & Recomendación & $\begin{array}{l}\text { Objetivo y } \\
\text { observaciones }\end{array}$ \\
\hline Programa & $\begin{array}{l}\text { Descripción de } \\
\text { contenidos } \\
\text { mínimos y } \\
\text { objetivos de } \\
\text { enseñanza } \\
\text { aprendizaje (año } \\
2018 \text { ) }\end{array}$ & $\begin{array}{l}\text { Se refiere } \\
\text { "Alumnos" en } \\
\text { objetivos y otras } \\
\text { partes del } \\
\text { documento. En } \\
\text { algunas ocasiones } \\
\text { incluye "los/las } \\
\text { estudiantes" }\end{array}$ & $\begin{array}{l}\text { Uso del lenguaje } \\
\text { no sexista } \\
\text { (inclusivo) para } \\
\text { construir visiones } \\
\text { del mundo } \\
\text { compartidas o } \\
\text { alternativas }\end{array}$ & $\begin{array}{l}\text { Fundamentado en } \\
\text { el marco de la ESI, } \\
\text { reconocer la } \\
\text { participación de } \\
\text { mujeres y varones } \\
\text { en la construcción } \\
\text { de las identidades } \\
\text { nacionales en sus } \\
\text { dimensiones } \\
\text { políticas, } \\
\text { culturales, } \\
\text { económicas, } \\
\text { científicas y } \\
\text { sociales. }\end{array}$ \\
\hline Cronograma & $\begin{array}{l}\text { Informativo. } \\
\text { Nombre de las } \\
\text { actividades. }\end{array}$ & No se detecta & & \\
\hline $\begin{array}{l}\text { Guía para la } \\
\text { realización de } \\
\text { Informes }\end{array}$ & $\begin{array}{l}\text { Recomendación } \\
\text { de estilo para la } \\
\text { realización de los } \\
\text { informes grupales. } \\
\text { La redacción se } \\
\text { encuentra en } \\
\text { imperativo y en } \\
\text { estilo de informe } \\
\text { técnico. }\end{array}$ & $\begin{array}{l}\text { Refiere a } \\
\text { "alumnos" }\end{array}$ & $\begin{array}{l}\text { Usar lenguaje } \\
\text { inclusivo (no } \\
\text { sexista). } \\
\text { Reemplazar por } \\
\text { alumnado, } \\
\text { personas } \\
\text { estudiantes, por } \\
\text { ejemplo. }\end{array}$ & $\begin{array}{l}\text { Visibilizar sujetos } \\
\text { subordinados y } \\
\text { ocultos en } \\
\text { enseñanza- } \\
\text { aprendizaje de la } \\
\text { ciencia y la } \\
\text { tecnología }\end{array}$ \\
\hline $\begin{array}{l}\text { Guía para las } \\
\text { autoevaluaciones }\end{array}$ & $\begin{array}{l}\text { Uso del portafolio } \\
\text { para desarrollar la } \\
\text { capacidad de } \\
\text { reflexionar sobre el } \\
\text { aprendizaje propio }\end{array}$ & $\begin{array}{l}\text { Utiliza lenguaje } \\
\text { inclusivo. Refiere a } \\
\text { personas } \\
\text { estudiantes y } \\
\text { personas }\end{array}$ & & $\begin{array}{l}\text { Último material } \\
\text { desarrollado. Aun } \\
\text { en optimización. } \\
\text { Requiere incluir } \\
\text { descripciones de }\end{array}$ \\
\hline
\end{tabular}




\begin{tabular}{|c|c|c|c|c|}
\hline & $\begin{array}{l}\text { en actividades del } \\
\text { quehacer del } \\
\text { laboratorio. }\end{array}$ & docentes. & & $\begin{array}{l}\text { secciones para } \\
\text { rubricas }\end{array}$ \\
\hline $\begin{array}{l}\text { Guías de Trabajos } \\
\text { Prácticos }\end{array}$ & $\begin{array}{l}\text { Guía para la } \\
\text { realización del } \\
\text { trabajo } \\
\text { experimental, en } \\
\text { laboratorio o } \\
\text { computacional. } \\
\text { Incluye objetivos, } \\
\text { breve introducción, } \\
\text { protocolos o } \\
\text { diseños } \\
\text { experimentales. } \\
\text { Más preguntas } \\
\text { guía. }\end{array}$ & $\begin{array}{l}\text { Refiere a cuerpo } \\
\text { docente y } \\
\text { estudiantado y } \\
\text { profesorado. } \\
\text { Ultima guía se } \\
\text { encuentra el } \\
\text { término "horas } \\
\text { hombre" transcrito } \\
\text { del software }\end{array}$ & $\begin{array}{l}\text { Objetivos } \\
\text { didácticos en } \\
\text { lenguaje inclusivo. } \\
\text { "horas de trabajo" } \\
\text { en vez de "horas } \\
\text { hombre" }\end{array}$ & $\begin{array}{l}\text { Se observa un } \\
\text { Proceso } \\
\text { progresivo de } \\
\text { incorporación del } \\
\text { enfoque de } \\
\text { género, en función } \\
\text { de las últimas } \\
\text { guías modificadas. }\end{array}$ \\
\hline $\begin{array}{l}\text { Guías de } \\
\text { resolución de } \\
\text { Problemas }\end{array}$ & $\begin{array}{l}\text { Problemas } \\
\text { cerrados y } \\
\text { abiertos. El } \\
\text { tratamiento de } \\
\text { estilo técnico con } \\
\text { predominio del } \\
\text { "Ud." }\end{array}$ & $\begin{array}{l}\text { "los autores" } \\
\text { cuando refiere a } \\
\text { algún trabajo } \\
\text { científico }\end{array}$ & & $\begin{array}{l}\text { En el marco de la } \\
\text { ESI sobre el } \\
\text { lenguaje, trabajar } \\
\text { sobre la valoración } \\
\text { de r textos } \\
\text { producidos tanto } \\
\text { por autores como } \\
\text { por autoras. }\end{array}$ \\
\hline $\begin{array}{l}\text { Presentaciones } \\
\text { teóricas (Power } \\
\text { point) }\end{array}$ & $\begin{array}{l}\text { Material de apoyo. } \\
\text { Técnico } \\
\text { descriptivo y } \\
\text { gráfico. }\end{array}$ & $\begin{array}{l}\text { * Ver comentario } \\
\text { en el texto }\end{array}$ & & \\
\hline $\begin{array}{l}\text { Bibliografía } \\
\text { específica (papers } \\
\text { científicos) }\end{array}$ & $\begin{array}{l}\text { Obtenidas de } \\
\text { revistas o } \\
\text { publicaciones } \\
\text { periódicas } \\
\text { científicas }\end{array}$ & $\begin{array}{l}\text { En las referencias, } \\
\text { se refiere a la } \\
\text { primera autoría, } \\
\text { sin definir si es } \\
\text { hombre o mujer }\end{array}$ & & $\begin{array}{ll}\text { En el marco de la } \\
\text { ESI sobre el } \\
\text { lenguaje: } \\
\text { valoración } \\
\text { textos producidos } \\
\text { tanto por autores } \\
\text { como por autoras. }\end{array}$ \\
\hline
\end{tabular}

Para el contexto educativo del Aula de RPP, se analizó el lenguaje -retórica e imágenes ilustrativas- y se encontraron rasgos y estereotipos de género donde subyace y persiste una visión androcéntrica de la ciencia. Se verifican las hipótesis propuestas: "En los materiales didácticos elaborados se transmiten estereotipos a través del lenguaje y las imágenes" y "Existen sesgos de género en la formación científica y tecnológica en la enseñanza superior".

Estudio 2: Detección de sesgos y estereotipos de género a partir del análisis de discurso en las producciones de las personas estudiantes 
En la comisión con cursada presencial (2019) y en cuanto a las dinámicas de grupo, a través del análisis del discurso, se observaron distintos tipos de tensiones. Algunas en cuanto a los tiempos, otras referidas a la distribución de tareas. Los grupos homogéneos (todos varones o todas mujeres) tuvieron dinámicas de grupo explicitadas diferentes a los mixtos. Algunos ejemplos se exponen a continuación:

1. Una de las estudiantes TFJ' del G2 (mixto), que en su portafolio reflexiona pero cumple parcialmente con las consignas y formatos solicitados, menciona en su autoevaluación final lo "difícil que fue lidiar con las diferencias en la forma de trabajo de los integrantes de grupo y conseguir realizar tareas equitativas, haciendo hincapié en el compromiso". El varón GT del G2 realiza la consigna parcialmente, describe y pocas veces reflexiona, aunque sin profundidad. Se propone metas pero no trabaja en ellas: "Me propongo trabajar en el laboratorio de manera cómoda y segura, sin tener que preguntar todo el tiempo si está bien lo que está realizando; poder organizar con sus compañeros las tareas, mejorar la realización de cálculos sin tener que consultar con profesores $o$ compañeros". En uno de los primeros trabajos prácticos menciona "pude realizar las tareas asignadas por el grupo". En su conclusión final menciona haber "superado obstáculos como realizar cálculos de las diluciones, y haber tenido dificultades en la organización con los integrantes del grupo". Se autopercibe con nota final 8 en rendimiento.

2. "Preciso que un compañero me explique los cálculos, tengo dificultades en entender los datos [...] Todavía no me siento segura y debo pedir que alguien también los verifique". Esta estudiante CM participa del G3 (grupo mixto conformado por un varón y tres mujeres). En general, en su autorreflexión esta persona describe y reflexiona (pero no profundiza) a lo largo de las 9 prácticas experimentales. El varón que participa del G3, sólo cumple con la consigna global que se realiza al final del cuatrimestre. En esta reflexión final menciona que "trabajó en grupo satisfactoriamente, intentó mejorar la comunicación con las personas que no conocía para facilitar el trabajo en conjunto, que reforzó su conocimiento en el manejo del laboratorio ya que tiene cierta confianza con lo que realiza por estar casi recibiéndose" (se auto percibe con un 8 o 9 en rendimiento).

3. Otra estudiante CV, perteneciente al G1 (todas mujeres), cumple con el formato solicitado en cuanto a las consignas dadas. Se propone ser más hábil y rápida para determinada tarea experimental (como realizar las cuentas mentalmente), quiere ser organizada y prolija, tiene miedo y preocupación. Coopera con las compañeras y se ayudan mutuamente. Se auto percibe con nota 8.

4. En el caso del G6 masculino, los tres participantes cumplieron con el formato solicitado en cuanto a las consignas dadas. En el porfolio describen las actividades

\footnotetext{
2 Las referencias a las personas estudiantes serán nominadas con etiquetas para poder identificar las subjetividades y mantener el anonimato.
} 
desarrolladas, reflexionan sobre su práctica pero sin profundidad. Las dinámicas de grupo no presentaron inconvenientes en cuanto a la organización de las tareas y el tiempo. Al ser el grupo con menos integrantes, todos participaron en todo equitativamente y sin que nadie "controle" el trabajo ajeno. Dos se auto-perciben con nota 8 y uno con 7.

En cuanto a la valoración de las capacidades, las subcategorías de confianza y seguridad se observaron mayoritariamente en las reflexiones femeninas. En la mayoría de ellas se explicita la falta de confianza y seguridad en el quehacer operativo del laboratorio y en la realización de los cálculos. Pero también se ha notado en algunos varones y muchos mencionan el miedo a no poder realizar o encarar una tarea. Sería conveniente cruzar variables y tener en cuenta la altura de la carrera en la que se encuentran (ya que pueden cursarla estudiantes con diferentes recorridos). Se observa autopercepción de componentes valorativos, cognitivos y emocionales que podrían relacionarse a estereotipos de género. Para un análisis más profundo, se requiere relacionar con otros indicadores. En todas las producciones se observó el uso del genérico masculino, y la auto-denominación en masculino en la mayoría de las mujeres (Autoevaluaciones, diciembre de 2019).

\section{Comisión 2020 Matutina Virtual:}

G1M (mixto): LM (varón), quien participó de este grupo mixto, incluyó en todas sus producciones vocablos relacionados al lenguaje inclusivo informal contemplando la inclusión de la "e" o de la " $x$ " para no utilizar el genérico masculino y así visibilizar a otros géneros no binarios. Mientras que CA (mujer), también visibiliza masculinos y femeninos pero con la forma binaria las/los:

Hola a todes. Como dicen mis compañerxs, [...] resto de mis compañeres (Autoevaluaciones de LM, agosto de 2020).

de mis compañeras/os de grupo, entre nosotras/os y consultas a las docentes, trabajo de todas/os, entre las/os integrantes y dispuestas/os a (Autoevaluaciones de CA, agosto de 2020).

En cuanto al balance general de LM (respecto de sus expectativas, debilidades y fortalezas), se perciben la autoconfianza y autosuficiencia. En el caso de CA, refiere a seguridad (confianza) y búsqueda de la perfección:

No me siento cómodo volcando mis reflexiones, metas, proyectos o sentimientos acá... no porque no crea que tenga que hacerlas, sino porque no me parece el espacio donde deba hacerlo"; "[...] no creo que haya evolucionado respecto a las debilidades que ya arrastraba como alumno, que siento se acentuaron con el ASPO, respecto a la procrastinación y la desorganización. Considero que pude explotar bastante bien mi capacidad "autodidacta". En cuanto a la calificación que me pondría, un 7 refleja un poco un balance entre mis principales debilidades organizativas-que no fueron 
mejoradas- y mis fortalezas respecto al abordaje de los temas (Autoevaluaciones de LM, agosto de 2020).

Mientras que CA, menciona "En particular noté diferencias en la manera en que llegué al primer parcial y al segundo: si bien mi nota fue similar, para el segundo pude llegar con más tiempo y seguridad en los conceptos tanto teóricos como prácticos". Y esto es resultado de haber mejorado el uso y organización del tiempo.

Es interesante notar como CA y LM tienen en mente valores profesionales y del quehacer científico que les motivan:

[...] Estoy bastante manija con terminar la carrera porque hace algo más de un año estoy en un laboratorio y siento que sirvo para el laburo en mesada o el diseño de experimentos etc. y me gustaría poder dedicarle más tiempo a eso que me gusta un montón (Autoevaluaciones de LM, agosto de 2020).

Este trabajo me resultó de particular interés, por lo tanto me sentí motivada a llevarlo a cabo. Interpeló a un interés personal que es la solución de problemas, lo cual también contribuyó a que fuera ameno completarlo. Se nos presenta con un objetivo que podemos alcanzar de diferentes maneras (Autoevaluaciones de CA, agosto de 2020).

G2M (mixto): Tanto MFG como AGP (ambas mujeres) se refieren a su compañera y compañero utilizando el masculino genérico; EC (varón) también utiliza el masculino genérico cuando se refiere a la totalidad de las personas del grupo: mis compañeros, ellos, a alguno, todos juntos, todos.

AGP presenta diferentes niveles de frustración, se retrotrae y no discute porque presenta dudas e inseguridades. En sus reflexiones es muy crítica sobre ella misma, y piensa que pensar alternativas distintas es inútil al estar aprendiendo:

Creo que mi mayor inconveniente es que no veo el panorama general y eso me bloquea al intentar comprender y dar sentido a lo que se realiza y posteriormente se pide. Tal vez si entendiera el panorama general podría darme cuenta si lo que pienso es correcto o no pero al tener dudas no discuto al respecto. Esto también me dificulta generar un esquema mental o diagrama ya que lo primero que necesito saber para realizarlo es justamente el objetivo al que quiero llegar. Una vez que pasa el tiempo voy comprendiendo lo que cada profesor desea que sepamos o el enfoque al cual se dirige pero al inicio es como una nebulosa. Tengo la mala costumbre de pensar en miles de alternativas distintas para un solo planteo, algo totalmente inútil cuando se está aprendiendo, esto me imagino que sería favorable una vez que se tienen todos los conocimientos ya que antes es más que nada pensar alternativas sin base que las sostenga, es decirfútiles. Desgraciadamente no creo que sea algo que pueda aprender en esta materia, es una cuestión que ya conozco de mi misma y aun no pude modificar (Autoevaluaciones de AGP, agosto de 2020).

MFG también presenta inseguridades, y menciona el miedo mientras que EC menciona el enojo, rabia y desesperación cuando no comprende o entiende algún tema y miedo frente a las evaluaciones: 
Yo mejoré mucho más, incluso me animé a procesar los datos sola. [...] Así que al principio, lo agarre con miedo pero después me tranquilicé y me fueron saliendo las cosas o vergüenza de opinar sobre el trabajo ajeno (Autoevaluaciones de MFG, agosto de 2020).

Casi fin de cuatrimestre, solo queda rendir el integrador (miedo). [...] Hay otros momentos donde se me hace muy difícil, sobre todo en algunas teorías donde surgen dudas y en el momento no pueden ser despejadas y momentáneamente, a nivel cerebral, se me pierde toda la información y me enojo conmigo mismo, pero luego se me pasa. Ese momento de rabia o desespero es una de las cosas que me gustaría ir mejorando. [...] Siempre uno tiene "vergüenza" o " cosa" de opinar sobre el trabajo del otro, pero como ya venimos trabajando en ese sentido, se me hizo más fácil. Por eso, otra de las enseñanzas que me llevo es la de "criticar" trabajos de otros con argumentos (cosa que al tener la teoría de las técnicas es posible) (Autoevaluaciones de EC, agosto de 2020).

G3M (mixto): Es interesante el cambio gradual que se observa en el caso de la estudiante SD (mujer) en cuanto al "cambio de código". En sus primeros aportes, refiere a los genéricos en masculino, aunque también la incluyen:

[...] tanto mi compañero como yo, supimos ayudarnos como compañeros, haciendo cada uno la parte que le tocaba y "corrigiendo" siempre cordialmente lo que hizo el otro, [...] estamos acostumbrados a procesar los datos que obtenemos nosotros experimentalmente [...] en el laboratorio por los alumnos que manipularon las muestras (Autoevaluaciones de SD, agosto de 2020).

Mientras que en su último aporte, hay un gran avance en cuanto a la visibilización de la presencia de compañeras mujeres y de su propia persona. Siendo que también se explicitan la auto-exigencia y el esfuerzo puesto en juego, además de las expectativas futuras como profesional en biotecnología. Se auto-percibe con nota final 9:

En cuanto a mi desempeño como alumna, debería descontarme al menos 1 punto por no haber cumplido con todas las tareas y considero que se debe cumplir con las obligaciones sin importar los problemas que uno pueda llegar a tener porque todos tenemos problemas y quizás haya un/a compañero/a que tuvo que pasar por una mala situación y sin embargo realizó todas las tareas en tiempo y forma, por lo que no sería justo para él/ella. Y todo ese esfuerzo para ser una profesional bien formada, que tenga aunque sea conocimientos básicos en cada una de las áreas, [...] poder servir también en donde se requiera de mi ayuda. Mi idea es ver todas las puertas que se me pueden abrir como biotecnóloga, ya que también me interesa mucho la criminalística y el medio ambiente, y me gustaría ver qué lugar podría ocupar yo como profesional en esas áreas (Autoevaluaciones de SD, agosto de 2020).

MER (varón), menciona sus metas, sus dudas y sus frustraciones... ¿reflejo de un mandato social?:

En realidad, aun no sé qué rama de biotecnología seguir. Me frustra pensar que hay compañeros que ya tienen re decidido que hacer, (compararse está mal, lo sé), o que saben a qué lab mandar cv, y yo todavía estoy como que no me decido que hacer. Yo 
siento que primero quiero recibirme y luego ver qué onda, ahora si eso está bien o no, no lo sé con exactitud (Autoevaluaciones de MER, agosto de 2020).

G4M (femenino, ex G1M): En el caso de MVR (mujer) se refiere a sí misma en masculino, ambas utilizan genéricos en masculino para hacer referencia tanto a su grupo como al gran grupo. Se auto percibe con nota entre 9 y 8 sin definirse por alguna de ellas (se toma un promedio para su evaluación 8,5 ). Esto muestra inseguridad en la toma de decisiones, y podría considerarse un sesgo de género adquirido. SR se autoevalúa con 8 :

Entiendo que no es algo fácil de llevar la situación actual, ni para ustedes ni para nosotros, sobretodo porque es algo totalmente nuevo y no todos estamos familiarizados con este mundo virtual. [...] la buena predisposición que tienen ambas docentes, [...] lo pude resolver pidiendo ayuda tanto a las docentes como a mis compañeros de trabajo. [...] que las docentes hayan tomado los consejos u observaciones por parte de los alumnos (Autoevaluaciones de MVR, agosto de 2020).

Hacia el final de sus reflexiones, al igual que otras personas, MVR comienza a visibilizar en su discurso a otros géneros, recurriendo al término informal que incluye $\mathrm{x}$ para el doblamiento de género:

[...] ver los trabajos de Ixs compañerxs. Es interesante la idea de realizar una crítica constructiva y a su vez poder recibir las de otrxs [...] que la comunicación entre alumnxs y docentes sea fluida y continua ya que todos estamos [...] de las docentes para con nosotrxs (Autoevaluaciones de MVR, agosto de 2020).

\section{Comisión 2020 Nocturna Virtual}

G1N (mixto): Este fue un grupo numeroso respecto a los demás grupos establecidos. Compuesto por ARD, Cl, IS (3 mujeres); AA y TR (2 varones), quienes se auto perciben con notas $9,9,7,7$ y 8 , respectivamente. Se puede observar que hay opiniones generales en cuanto a la organización del tiempo y las dinámicas grupales en la elaboración de los informes. Es un grupo donde sus integrantes se conocen en su forma de trabajar y además presentan lazos de amistad. Trabajan en conjunto desde hace varios cuatrimestres. Se aporta individualmente y se realiza el ejercicio de consenso para la toma de decisiones. Se resaltan la eficiencia, el criterio, el buen funcionamiento, como valores positivos. Las cinco personas utilizan genéricos masculinos en sus discursos: los profesores, todos, todos nosotros, cada uno de nosotros, alumnos, compañeros, juntos, amigos. A modo de ejemplo:

Me anoté junto con amigos con los que vengo cursando hace varios años, por lo que conocemos nuestros fuertes y debilidades. Realmente considero que cada vez que me junto con mi grupo saco provecho al máximo del TP, ya que todos nosotros somos muy detallistas en la redacción, comprensión y comparación de nuestras ideas. Todos tenemos un carácter similar, en el que creemos fuertemente en lo que cada uno entendió durante las clases, pero a su vez contamos con la habilidad de escuchar a los demás, y la combinación de estas dos cosas nos permite siempre armar un debate muy grande, que está muy bueno, aunque a su vez tiene la desventaja de que cada 
vez que hacemos un trabajo, nos demanda mucho tiempo (Autoevaluaciones de TR, agosto de 2020).

Respecto de las frustraciones, algunas se refieren al contexto de ASPO y otras al quehacer científico, donde denota el nivel de exigencia, la expresión de miedos e inseguridades personales:

Al comenzar la cursada tenía muchas expectativas y miedos. Por un lado nunca tuve clases virtuales y no sabía con qué podría encontrarme, y por otro, este cuatrimestre representaba la finalización de una gran etapa en mi vida. Al pasar las semanas me encontré abrumada entre las tres materias que curso, hasta que me empecé a amigar con la virtualidad. Realmente no sé cómo llegue hasta el final del cuatrimestre sin abandonar ninguna materia, porque me sentí frustrada y estuve a punto de hacerlo muchas veces, aunque abandonar una materia por primera vez en el último cuatrimestre no me agradaba (tampoco sabía que debía dejar porque me gustan los temas dictados) (Autoevaluaciones de Cl, agosto de 2020).

En la realización de este TP4 me sentí más cómoda ya que todo dependía de mí. Hubo un día en el que me sentí muy frustrada debido a que no lograba cumplir con el objetivo de la purificación total de la proteína porque había un contaminante que no podía eliminar, pero luego cuando lo consulté me dijeron que no era error mío así que ahí me tranquilice. Con el correr del cuatrimestre logré acomodarme y llevar a cabo el cuatri con todas las expectativas con las cuales lo inicié. Pese a todo, supe sobrellevarlos de la mejor manera posible, sé que fue complicado para todos, tanto alumnes como docentes, y creo que todos pusimos lo mejor de nosotros (Autoevaluaciones de IS, agosto de 2020).

A partir del primer parcial, creo que me puse mucho más participativo, al menos en las reuniones con mi grupo de estudio y gracias a ellos/as pude remontar (Autoevaluaciones de AA, agosto de 2020).

Ya sobre el final de la cursada, se empieza a notar la existencia de "code-switching"3 o cambio de código lingüístico. Resulta motivador encontrar comentarios como el siguiente, pues muestra que las mujeres mantenemos la idea de acceder al ejercicio de la profesión en ámbitos tradicionalmente masculinizados como es el industrial, $\mathrm{Y}$ que como cuerpo docente, transmitimos que todos y todas pueden acceder a ello:

Creo también que esta materia me ayudó a terminar de elegir qué es lo que me gustaría hacer en un futuro para nada lejano, y me encantaría formar parte de alguna industria en la cual pueda desempeñarme dentro de esta temática y capacitarme más adecuadamente. Siento que mi desempeño en la cursada fue bueno, estoy contenta y concluyo colocándome una nota numérica personal (a mi parecer) de 9. (Autoevaluaciones de ARD, agosto de 2020).

G2N (mixto): Integrado por BB (mujer); GH y LH (varones). Tanto BB como GH se auto perciben con nota 9 , mientras que LH se auto percibe con 6 por "la escasa participación en foros y consultas". Este grupo mixto también refiere a genéricos en masculino: "los

\footnotetext{
${ }^{3}$ Code-switching o cambio de código, término lingüístico para denominar el pasaje entre lenguas, cuando se está aprendiendo un nuevo lenguaje.
} 
profesores, los alumnos, los integrantes, cada uno, y aun refiriéndose al resto del grupo, compuesto de un hombre y una mujer". Las personas integrantes de este grupo presentan distintos puntos de vista sobre las interrelaciones grupales con mención de la seguridad y la confianza. Hay quienes coinciden y hay quienes se vieron en subordinación, como es el caso de LH, quien además menciona el miedo a participar y hacer consultas. Esto podría inferirse como temor a la exposición, a fallar en el modelo de masculinidad hegemónico predominante.

En lo que respecta al desempeño grupal en el TP 1, pude observar una buena disposición de los integrantes del grupo. Una vez razonadas las determinaciones que se debían hacer, cada integrante realizaba los cálculos necesarios para finalmente comparar resultados y ver que los valores obtenidos sean los correctos. Con el tiempo se pudo lograr un trabajo más fluido, donde cada uno aportaba lo necesario para hacer un buen análisis del informe (Autoevaluaciones de BB, agosto de 2020).

La parte de la redacción es algo que me cuesta y en lo que tardo mucho. Suelo consultar mucho a mis compañeros si piensan que algo que escribí está mal. Tanto a mí como a mis compañeros no nos molesta editar o hacer sugerencias sobre algo que puso el otro (Autoevaluaciones de GH, agosto de 2020).

[...] no colaboré mucho en la parte de resultados del TP1 porque tenía problema con la realización de los gráficos por lo que mis compañeros fueron de gran ayuda para realizarlo y solo seguía a ellos. Por no me siento incómodo trabajando con ellos. En informes anteriores tenía vergüenza de cómo integrarse y poner las dudas, haciendo que el informe tarde más, pero en este logré integrarme más con ellos por lo que no tuvimos inconvenientes en realizarlo al discutir dudas y resultados. [...]. En esta materia tuve una casi nula participación en los chats debido a que tengo poca participación siempre, siendo virtual como presencial. Puede ser que sea por timidez o también porque ya actuó siempre de esta manera. Pero es algo que debo cambiar, ya que debo perder miedo al realizar consultas (Autoevaluaciones de LH, agosto de 2020).

Las personas integrantes de este grupo presentan distintos puntos de vista sobre las interrelaciones grupales con mención de la seguridad y la confianza. Hay quienes coinciden y hay quienes se vieron en subordinación, como es el caso de $\mathrm{LH}$, quien además menciona el miedo a participar y hacer consultas. Esto podría inferirse como miedo a la exposición, a fallar en el modelo de masculinidad hegemónico predominante.

G3N (mixto): Compuesto por BC, NT (mujeres) y $A B$ (varón), quienes se auto percibieron con notas 8,6 y 9, respectivamente. Este grupo mixto también refiere a genéricos en masculino: los integrantes, todos, los profesores, los docentes, juntos, con mis compañeros, cada uno. Se notan tensiones en la relación de grupo. En el relato de BC podría decirse que se observan aptitudes de perfección, cuidado y esmero, así como rasgos de autosuficiencia: 
Respecto de la primera práctica de análisis de datos: El desarrollo del informe se realizó con buena predisposición de los integrantes del grupo, pese a que la mayoría comenzamos a trabajar, debido a la cuarentena, en horarios más extendidos a los normales. En cuanto a la segunda, se logró una mejor división de trabajo en grupo, en el que todos hicimos aportamos de igual manera, ayudándonos y aportando entre todos. En el TP3, tuvimos problemas con una de las integrantes del grupo ya que desde el TP 2 no viene aportando mucho a los informes por lo que se hace más tedioso tener que hacerlo de a 2 personas. Se habló con ella y se le planteó que aporte a los informes. En todas sus intervenciones se refiere a los profesores (Autoevaluaciones de $A B$, agosto de 2020).

En cuanto a las destrezas, al realizar los informes descubrí que tengo habilidad para detectar inconsistencias, errores o faltantes y lograr debatir con mis compañeros la mejor forma de mejorarlos". En cuanto a las áreas débiles, están la de interactuar con los demás y en participar en las retroalimentaciones. Cuando tengo que resolver algo que no me sale, no me gusta ir directo a la ayuda de alguien, prefiero pensar los ejercicios algunos días, quizás se me ocurre alguna solución cuando estoy en el trabajo por ejemplo. Y es por eso que no leía las respuestas de los seminarios o consultas hasta no tener los ejercicios resueltos. Llevé muy mal la materia en términos de tiempos. En cuanto a las áreas fuertes, de leer y analizar lo que escribo y ser resolutiva ante problemas que surgían. En cuanto a mi grupo de laboratorio me sentí muy cómoda, casi nunca pudimos estar los 3 en un horario juntos en algún TP porque cada uno tenía horarios diferentes, pero sin embargo había retroalimentación y debate sobre las consultas que uno dejaba. Como nota general me pondría un 8 (Autoevaluaciones de BC, agosto de 2020).

[...] tenían los docentes hasta mis compañeros. Tuve problemas con ciertas tareas que había que hacer, no porque costara, sino porque no estaba al tanto, reconozco que esto fue mi culpa por no prestar mayor atención. Tardé en acostumbrarme al uso del campus y estar acostumbrada a la cursada presencial. Como nota final me pondría un 6. Creo que aprendí mucho, pero también considero que tuve problemas al razonar ciertos conceptos importantes de la materia (Autoevaluaciones de NT, agosto de 2020).

Las dos personas que se autoevalúan con calificación 6 (G2N y G3N), lo hacen por escasa participación.

G4N (masculino): En cuanto a las dinámicas para la elaboración de informes refieren a que cada integrante hace una parte del trabajo y luego explica al resto. La comunicación entre ellos es fluida. Los tres integrantes (MBI, MBo, EC) se auto perciben con 9. Muestran autoconfianza y autosuficiencia. El estudiante EC menciona sus dificultades y logros a lo largo del cuatrimestre. En su cierre, su nivel de desempeño en los aspectos de responsabilidad, participación, contribución, colaboración, construcción colaborativa, compromiso fue en promedio de muy bueno (bastante). Hace mención al cuerpo docente (genérico inclusivo). El estudiante MBI reflexiona:

Mis metas son asimilar la mayor cantidad de contenido posible y aprender a pensar de una forma más parecida a la que lo hacen dentro de las empresas para facilitar mi inserción en una de estas. En un principio pensé que el desfase de altura de la carrera en la que me encontraba con respecto a mis compañeros de grupo podría llegar a dificultar el consenso en algunos aspectos del informe como la redacción u 
organización, esto fue sólo un prejuicio que tuve luego de realizar el primer informe. Luego de entrar en confianza y poder dialogar con mayor facilidad con mis compañeros, pudimos complementarnos de forma más eficiente y consensuada. Para cerrar esta autoevaluación, me gustaría mencionar que cumplí con la gran mayoría de objetivos y metas y con el trabajo en equipo para realizar los TPs. Asimismo aprendí muchísimo y me siento más sólido como estudiante y futuro biotecnólogo. Por tales motivos, pienso que no estaría mal autocalificarme con un nueve (Autoevaluaciones de $\mathrm{MBI}$, agosto de 2020).

En las autoevaluaciones se evidencian subjetivamente las dinámicas que se ponen en juego en la elaboración de los informes grupales así como también las valoraciones de las capacidades (como confianza y seguridad) y el rendimiento individual. En algunos casos analizados se encuentra autopercepción de sesgos y estereotipos de género. Con ello se valida la hipótesis de "Se mantienen valores y creencias sexistas (expectativas, actitudes y prácticas) con efectos sobre la propia valoración y autopercepción que las estudiantes tienen de sus capacidades y posibilidades en la formación científica y en su futuro profesional".

En las autopercepciones se detectaron valores de autosuficiencia, autoconfianza, liderazgo e iniciativa (típicamente asignados a la masculinidad), así como también cualidades y aptitudes como perfección, cuidado, detallistas, y subordinación, comúnmente asignadas como femeninas. Sería interesante sumar alguna herramienta de trabajo colaborativo para realizar un seguimiento de las dinámicas de grupo, de esta manera evaluar cómo son los roles y si hay diferencias en las actividades y actitudes en relación al género. Lo mismo observar que interacciones y dinámicas suceden en el quehacer experimental para las comisiones 2020.

En general, tanto mujeres como varones de todas las comisiones presentan el uso común del masculino genérico para la denominación de los conjuntos. Las mujeres, para autodenominarse o denominarse dentro de un grupo, en la mayoría de los casos también utilizan el genérico masculino.

Durante el primer cuatrimestre de 2020, las docentes comenzamos a incluir y visibilizar a las mujeres y a realizar el ejercicio consciente de dejar de usar el genérico masculino en todos los avisos, mensajes, producciones audiovisuales, e intervenciones... y notablemente ya al final del mismo más personas empezaron a incluir y visibilizar a otros géneros, así como a auto percibirse en su género explicitándolo. Esto muestra que nos encontramos frente al "code-switching" mencionado previamente.

Como ejercicio complementario y como nota de color, a continuación se recurre a las Nubes de palabras. Estas son utilizadas como herramienta de representación visual de todas las palabras que conforman un texto. El tamaño de letra del término se correlaciona con la frecuencia de aparición del mismo. Se contemplan todas las palabras contenidas en las autoevaluaciones, focalizando en ideas y conceptos, acciones. Se eliminan conectores y preposiciones, números y palabras específicas de la disciplina. Para cada comisión, se dividieron las producciones por la categoría del género. El uso de las palabras fue similar 
tanto para mujeres como para varones. Siendo Trabajo, Todo, Materia, TP, Informe, Nos, Tiempo, Creo, Mucho, Poder, las 10 más frecuentes para ellas; mientras que para ellos fueron Materia, Informe, TP, Parte, Todo, Trabajo, Mucho, Grupo, Creo y Análisis.
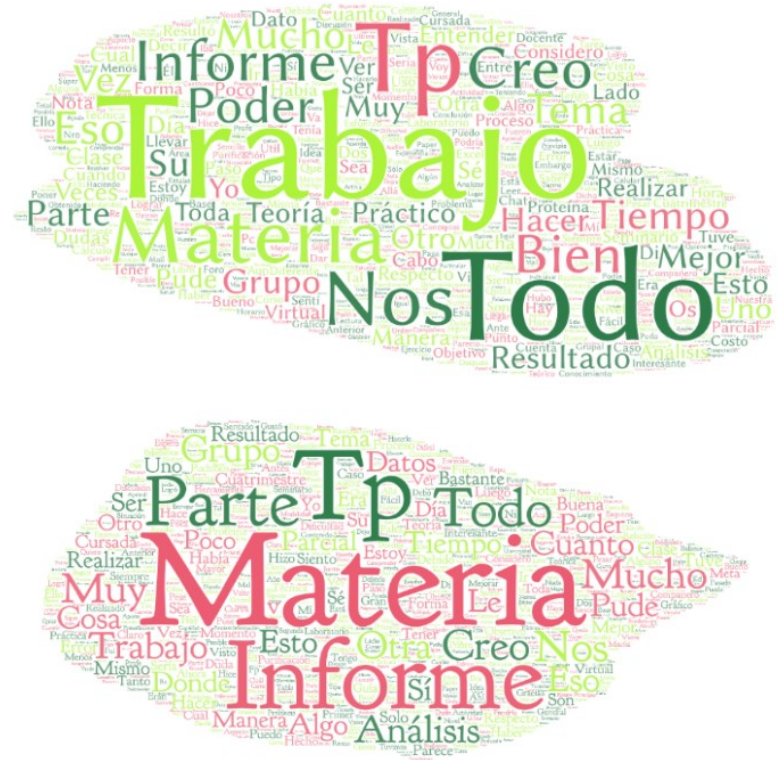

Nube de palabras proveniente de las Autoevaluaciones conjuntas de mujeres (izq) y varones (der) de ambas comisiones 2020.

Estudio 3: Análisis de las autopercepciones (autoevaluaciones) ¿Hay diferencia en cuanto a rendimiento vs fracaso por ser hombre o ser mujer?

En el siguiente gráfico (grafico 1) se muestra el rendimiento auto percibido para la comisión 2019 (cursada presencial) siendo el promedio de 7,9. Del total de varones que realizaron la actividad (8), el $75 \%$ se auto percibe con nota 8 y el $25 \%$ restante con notas menores (siendo 6 la más baja). Respecto del total de mujeres (24), el $25 \%$ se auto percibe con nota mayor a 8 , el $45 \%$ con 8 , y el $30 \%$ restante con notas menores a 8 siendo 6 el mínimo. A priori, esta información precisaría complementarse con las argumentaciones subjetivas que las fundamentan y además ser cotejada frente a las evaluaciones del profesorado. 


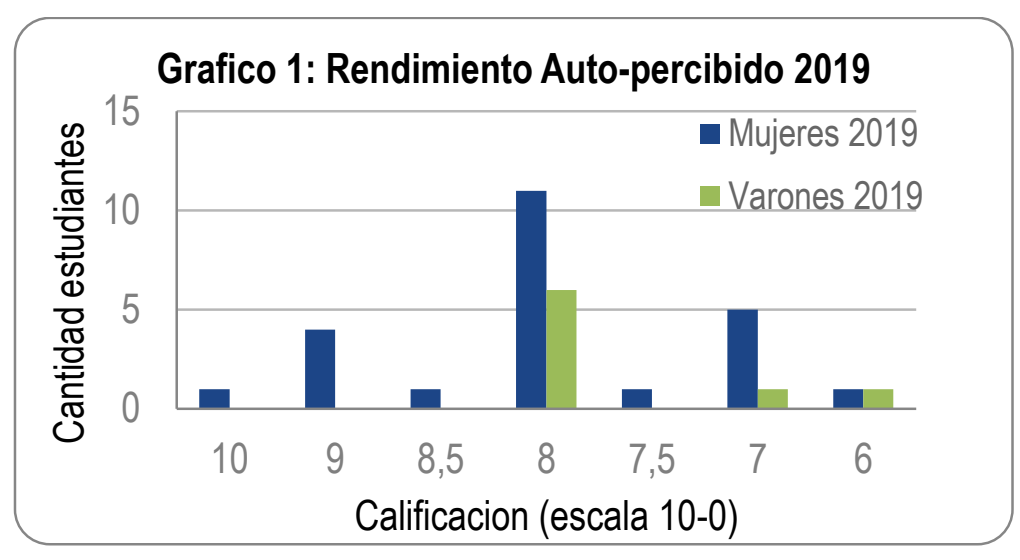

Sobre el rendimiento auto percibido para la comisión 2020 (cursada virtual), considerando ambas comisiones como una única comisión, el promedio general resulta en 8,1 . Del total de varones (11) el $45,4 \%$ se auto percibe con nota mayor a 8 , el $27,3 \%$ con 8 y el $27,3 \%$ restante con menores (siendo 6 la más baja). Respecto del total de mujeres (12), el $41,5 \%$ se auto percibe con nota mayor a 8 , el $41,5 \%$ con 8 , y el $17 \%$ restante con notas menores a 8 siendo 6 el mínimo (gráfico 2).

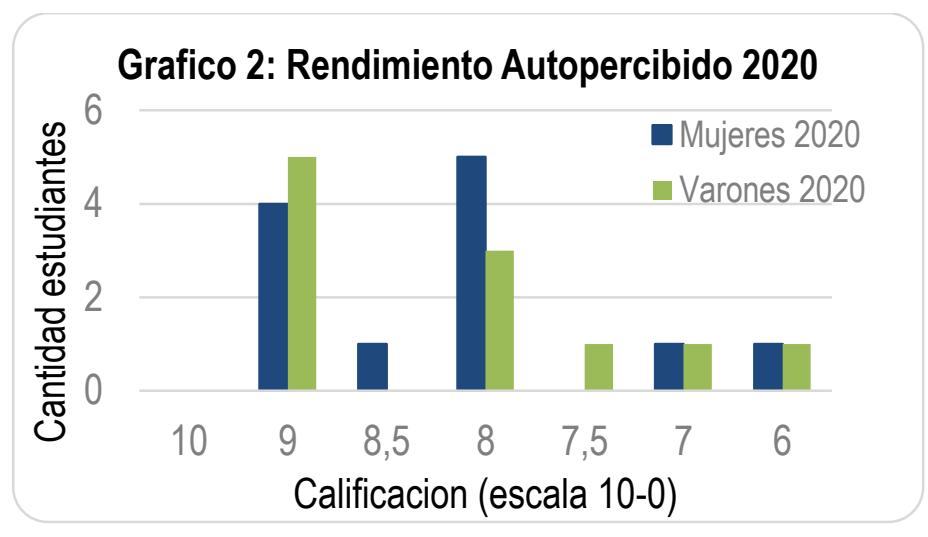

En el gráfico 3 se realiza un comparativo entre ambos años. La nota media para las mujeres 2020 y varones 2020, es 8,1 , mientras que para las mujeres 2019 resulta en 8 y los varones 7,6 . Se observan distribuciones diferentes. 


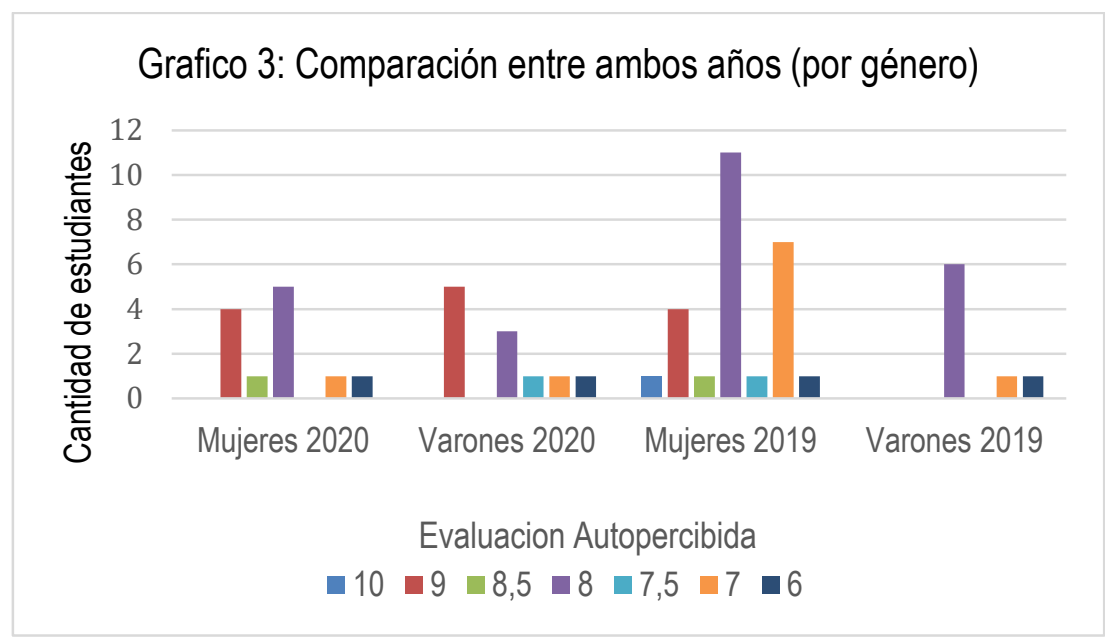

Se precisaría un análisis más exhaustivo y otras herramientas para responder la pregunta del tercer estudio. Además de comparar con las notas reales de cierre de actas, cuestión pendiente para las comisiones 2020.

\section{Conclusiones y acciones propuestas de intervención pedagógica}

Finalmente, se encontró que en las prácticas de enseñanza de RPP se fomentan y/o reproducen estereotipos de género a través del discurso y del quehacer profesional en el aula. Se detectaron rasgos sexistas en las producciones docentes que podrían ser desfavorables para las mujeres. Esto puede influir en los aprendizajes científicos, en la motivación y en los intereses del estudiantado. También puede afectar la percepción respecto de la aplicabilidad de las ciencias en la vida cotidiana. Desde el cuerpo docente, se propuso entonces incorporar la perspectiva de género, para cambiar la práctica pedagógica excluyente y fomentar el carácter inclusivo (la ciencia para todas y todos).

En las autoevaluaciones, se han detectado e inferido creencias, expectativas y valoraciones referidas a las capacidades y aptitudes de varones y mujeres por medio de dimensiones psicosociales (afectivas, emocionales, toma de decisiones, relaciones entre pares). Los estereotipos internalizados en general afectan al auto concepto de la persona, los procesos cognitivos, las aptitudes intelectuales y el desempeño en la ejecución de tareas. Pero en cuanto a las autopercepciones (Estudio 3), no se ha podido establecer si hay diferencia en cuanto a rendimiento vs fracaso por ser hombre o ser mujer.

También se ha detectado el predominio del uso del lenguaje sexista, tanto en el lenguaje científico como en el cotidiano. Sin embargo, hacia el final del cuatrimestre 2020 en muchas intervenciones estudiantiles se comenzó a utilizar el lenguaje inclusivo, en diversas formas. Esto muestra que existe un pasaje entre lenguas (code-switching) típico de cuando se está aprendiendo un nuevo lenguaje. 
Para construir una imagen de ciencia inclusiva desde el aula, es recomendable pensar en lo que se comunica y se transmite, ya sea desde la oralidad como desde las representaciones semióticas de los materiales didácticos y producciones docentes. Repensar el lenguaje y la representación visual en los libros de texto y en el material didáctico (texto, guías, material audiovisual, etc.) puede ayudar a eliminar las suposiciones inconscientes de género que restringen el descubrimiento y la innovación. En concordancia, eliminar metáforas científicamente no sólidas e incorporar ejemplos e ilustraciones más neutrales al género. Es importante evaluar qué tipo de ejemplos se brindan en la argumentación científica y si presentan sesgos de género asociados, evitando asociar a modelos y valores estereotipados. La ejemplificación repercute en la percepción que puede tener el estudiantado con respecto a la aplicabilidad de las ciencias en la vida cotidiana y en los estereotipos en el aula. Cabe aclarar, que en el lenguaje cotidiano también existen y se reproducen estos patrones, ya que son reflejo de la cultura predominante. Siendo entonces una problemática trasversal a ambos discursos. También evitar alusiones a modelos masculinos frente a femeninos estereotipados, en función de lo que son, lo que hacen o como se relacionan. Esto podría abordarse mediante la visibilización y recuperación histórica de mujeres científicas y sus aportes al campo disciplinar. Incluir el lenguaje no sexista (inclusivo) o denominaciones neutras para construir visiones del mundo compartidas o alternativas para comenzar a visibilizar personas subordinadas y ocultas en la enseñanza y el aprendizaje de la ciencia y la tecnología. En síntesis, promover la educación científica inclusiva para construir una ciencia inclusiva. $Y$ así, contribuir a reconocer la participación de mujeres y varones en la construcción de las identidades científicas y sociales tal como se recomienda en la Ley 26.150 de Educación Sexual Integral (ESI) (Ley 26.150, 2006).

Esto va en concordancia con lo que propone Johana Camacho (2018), quien plantea el abordaje desde la investigación en Didáctica de las ciencias para la construcción de educación científica no sexista con perspectiva de género. Ella sugiere aportes desde dos dimensiones, una epistemológica y otra pedagógica didáctica, como ser:

- Considerar, enriquecer e incorporar miradas de las teorías criticas feministas para contraponer a la visión patriarcal, androcéntrica y tradicional, en la construcción del conocimiento. De esta manera problematiza la propia naturaleza del conocimiento científico y sus mecanismos de producción, enseñanza, valoración y aplicación.

- Eliminar los estereotipos de las producciones docentes (guías de estudio, textos, imágenes, recursos audiovisuales, internet, etc.) y proponer la inclusión de nuevos contenidos y bibliografías no sexistas.

- Repensar las prácticas pedagógicas, las creencias del profesorado, para modificar las representaciones sociales (quehacer en las practicas, roles estereotipados). 
Teniendo en cuenta las observaciones se propone entonces producir material didáctico para RPP que no legitime diferencias sociales sobre la base de los sexos. Que además visibilice a las mujeres y otras diversidades en la enseñanza y el aprendizaje de la ciencia y la tecnología. De forma tal de romper con el ciclo y dejar de reproducir -en la enseñanza del conocimiento científico- el sexismo y androcentrismo reflejados en la práctica científica. De esta manera aspirar a aportar a la construcción del conocimiento humano, más plural e inclusivo.

Carmen Solís-Espallargas (2018) en su trabajo menciona y reflexiona... "hablar de género en la enseñanza de la ciencia significa comenzar por el análisis del proceso de socialización que han tenido los docentes en formación y cómo en su proceso personal se han interiorizado los estereotipos de género y la influencia que pueden tener sus prácticas de enseñanza en el aula. Significa demandar la formación necesaria en las facultades de Educación tanto para el profesorado universitario como para el estudiantado con el fin de superar la brecha de género existente en la enseñanza de las ciencias y la inclusión de este enfoque en los diseños curriculares" (p. 3602-2). Sería interesante entonces integrar la dimensión de género en los contenidos curriculares de enseñanza superior. En este caso de estudio sería un aporte individual de un equipo docente, resultando en una mera propuesta de personas individuales que presentan interés, sensibilización y conciencia sobre la temática. Para que realmente haya un cambio significativo, la propuesta también tendría que ser acompañada por políticas de gestión institucional. Algunas universidades y centros de investigación de América Latina se encuentran implementando diversas iniciativas y/o medidas para revertir las desigualdades de géneros en diversos aspectos de la vida académica. Dentro de ellos, una medida es transformar los diseños curriculares. Este proceso se encuentra en construcción (UNESCO, 2019).

A modo conclusivo, se han diagnosticado, detectado y visibilizado parcialmente valores y sesgos de género que operan en el contexto de la educación científica en el Aula de Recuperación y Purificación de Proteínas. Por ello, me llamo a reflexionar sobre mi propia práctica docente desde un enfoque de género para elaborar experiencias y prácticas de enseñanza y de aprendizaje no sexistas. De esta manera, también reflexionar sobre la existencia de prejuicios ideológicos que se asumen como verdades demostradas y son dados por el modelo hegemónico masculino, sobre cual imagen de ciencia se está transmitiendo en el aula y cuál quisiera transmitir. De modo tal que, desde la educación, pueda generar o elaborar herramientas de ruptura de los mecanismos que sustentan el ciclo.

\section{Agradecimientos}

Al Dr. Mariano Grasselli, docente titular de la asignatura por el espacio y oportunidades de crecimiento; al estudiantado de Recuperación y Purificación de Proteínas; así como también al CONICET y a la UNQ. 
Un agradecimiento especial a la Dra. Silvia Porro, directora del GIECIEN, por las sugerencias y correcciones brindadas.

\section{Referencias bibliográficas}

Autoevaluaciones (agosto-diciembre, 2019). Producciones escritas del estudiantado de la comisión 2019 de la Asignatura Recuperación y Purificación de Proteínas. Licenciatura en Biotecnología, Universidad Nacional de Quilmes.

Autoevaluaciones (abril-julio, 2020). Producciones escritas del estudiantado de las comisiones nocturna y matutina 2020 de la Asignatura Recuperación y Purificación de Proteínas. Licenciatura en Biotecnología, Universidad Nacional de Quilmes.

Bonder, G. (Coord.) (2017). Informe "Infancia, Ciencia y Tecnología: un análisis de género desde el entorno familiar, educativo y cultural". Cátedra Regional Mujer Ciencia y Tecnología en América Latina, UNESCO. Recuperado en: http://www.catunescomujer.org/wpcontent/uploads/2017/11/STEM.pdf.

Camacho, J. (2018). Educación científica no sexista. Aportes desde la investigación en Didáctica de las ciencias. Revista Nomadías (25), 101-120. Doi:10.5354/07190905.2018.51508.

Colás Bravo, P. y Villaciervos Moreno, P. (2007). La interiorización de los estereotipos de género en jóvenes y adolescentes. Revista de Investigación Educativa, 25(1), 35-38. Recuperado a partir de https://revistas.um.es/rie/article/view/96421

Corbalán, M. S. y Pérez Scalzi, A. (2019). Género y tecnología como oportunidades de ampliar la ciudadanía. Alianza Latinoamericana para la Tecnología Cívica (ALTEC), Fundación Luminate y Fundación Avina. Consultora PARES Recuperado de: https://pulsante.org/wp-content/uploads/2020/07/Guia-Nuevas-ciudadanias-genero-ytecnologia-como-oportunidades-para-su-ampliacion.pdf

Cuenca Sánchez, M. (2018). La ciencia y sus olvidadas: los sesgos de género y el androcentrismo en la construcción del conocimiento científico. Revista Estudios Culturales 11 (22), 43-55.

D’Onofrio, M. G. y Tignino, M. V. (2018). Indicadores diagnósticos sobre la situación de las mujeres en ciencia y tecnología en Argentina y Banco de acciones en género y ciencia, Taller Mujeres en ciencia y tecnología: hacia una participación con equidad; Ministerio de Educación, Cultura, Ciencia y Tecnología (MECCYT); Ciudad Autónoma de Buenos Aires. Disponible en: https://www.argentina.gob.ar/sites/default/files/presentacion diagnostico mujeres en cien cia y tecnologia 14-9-2018 meccyt.pdf 
Ley 26.150 (2006). Programa Nacional de Educación sexual integral (ESI). Argentina, 23/10/2006. Disponible en: http://servicios.infoleg.gob.ar/infolegInternet/anexos/120000124999/121222/norma.htm

Flores Palacio, F. (2012). Representación social y Género: una relación de sentido común. En N. Blázquez Graf, F. Flores Palacios y M. Ríos Everardo (coords.). Investigación Feminista. Epistemología, metodología y Representaciones sociales (págs. 339-358). Colección Debate y Reflexión. México, UNAM. ISBN 978-607-02-1286-4. Disponible en: http://209.177.156.169/libreria cm/archivos/pdf 1307.pdf

Franchi, A. Palomino, M., Cano Colazo, M. V. Jeppesen, C., Kochen, S. (2016). Proyecto "Desigualdades de género de las trayectorias Científicas". Recuperado de: http://www.ragcyt.org.ar/publicaciones

http://www.ragcyt.org.ar/descargas/5865 doc.pdf.

Centro REDES (2018). Programa de estudios "El enfoque feminista en la filosofía de la ciencia”, Dra. Myriam García Rodríguez. Centro de Estudios sobre Ciencia, Desarrollo y Educación Superior. Recuperado de: http://www.centroredes.org.ar/index.php/enfoquefeminista-filo-cyt/

Schiebinger, L., Klinge, I., Paik, H. Y., Sánchez de Madariaga, I., Schraudner, M., \& Stefanick, M. (Eds.) (2011-2020). Gendered Innovations in Science, Health \& Medicine, Engineering, and Environment (genderedinnovations.stanford.edu). Science Case Studies. Textbooks: Rethinking Language and Visual Representations (s./f.). Recuperado de: https://genderedinnovations.stanford.edu/case-studies/textbooks.html.

González García, M. I. \& Pérez Sedeño, E. (2002). Ciencia, Tecnología y Género. Revista Iberoamericana de Ciencia, Tecnología, Sociedad e Innovación 2.

González, M. I. \& Fernández Jimeno, N. (2016). Ciencia, tecnología y género. Enfoques y problemas actuales. Revista Iberoamericana de Ciencia, Tecnología y Sociedad - CTS, 31(11), 51-60.

González Ramírez, M. A. (Coord.) (2008). Mujeres y Hombres, ¿qué tan diferentes somos? Manual de sensibilización en perspectiva de género. México: Instituto Jalisciense de las Mujeres. Recuperado de: http://cedoc.inmujeres.gob.mx/ftpg/Jalisco/jal04.pdf

Lafuente Duarte R., Barandiarán S., Cartechini J., Estellés M., Granara G., Lapido N., Tignino, M. V. (2020). Diagnóstico sobre la situación de las mujeres en ciencia y tecnología. Documento de trabajo $N^{\circ} 1$, Febrero 2020. Programa Nacional para la lgualdad de Géneros en Ciencia, Tecnología e Innovación. Ministerio de Ciencia, Tecnología e Innovación, Argentina. Recuperado de: diagnostico sobre la situacion de equidad de las mujeres en ciencia y tecnologia.pd f (argentina.gob.ar) 
Manassero, M. A. \& Vázquez, A. (2002). Los estereotipos de género y el lenguaje en los libros de texto de ciencias. Cultura y Educación 14(4), 415-429. DOI: https://www.tandfonline.com/doi/abs/10.1174/113564002762700880

Manassero, M. A. \& Vázquez, A. (2003a). Los estudios de género y la enseñanza de las ciencias. Revista de Educación 330, 251-289.

Manassero, M. A. \& Vázquez, A. (2003b). Las mujeres científicas: un grupo invisible en los libros de texto. Revista Investigación en la escuela 50, 31-45. Recuperado de https://idus.us.es/handle/11441/60954

Mata Coca, I. M. (2002). Análisis descriptivo del lenguaje sexista en un texto universitario desde la perspectiva de la coeducación. Eúphoros 4, 65-80. Recuperado de: https://dialnet.unirioja.es/servlet/articulo?codigo=1183012

Pastor Antequera, M. C. \& García Fernández, A. (2011). Patrones de género en la enseñanza de las ciencias. Un análisis comparado de las estrategias políticas educativas europeas actuales. Ministerio de Ciencia e Innovación: Libro Blanco. Situación de las Mujeres en la ciencia española. Madrid: Unidad de Mujeres y Ciencia.

SITEAL, UNESCO (2019). Informe sobre Educación y Género. Recuperado en: siteal educacion y genero 20190525.pdf (unesco.org)

Solís-Espallargas, C. (2018). Inclusión del enfoque de género en la enseñanza de las ciencias mediante el estudio de biografías de mujeres científicas. Revista Eureka sobre Enseñanza y Divulgación de las Ciencias 15(3), 3602. doi: 10.25267/Rev_Eureka_ensen_divulg_cienc.2018.v15.i3.3602 Recuperado en: https://revistas.uca.es/index.php/eureka/article/download/4049/3943

Suárez Tomé, D. \& Bello, L. F (2017, 25 de febrero). No hay Sócrates sin Diotima: sobre androcentrismo y sexismo en filosofía. Ecofeminita. Nota recuperada de: https://ecofeminita.com/no-hay-socrates-sin-diotima-sobre-androcentrismo-y-sexismo-enfilosofial

UNESCO, Cátedra Regional Mujer, Ciencia y Tecnología en América (2019). Planes de Igualdad de Género en universidades y centros de investigación: antecedentes y estrategias. Informe final. Recuperado en: www.cateunescomujer.org Vázquez-Cupeiro, S. (2015). Ciencia, estereotipos y género: una revisión de los marcos explicativos. Convergencia. Revista de Ciencias Sociales, 22 (68), 177-202. Recuperado de: https://www.redalyc.org/articulo.oa?id=105/10536227007.

Velasco, M. L. Vázquez Rolland, D., Ibáñez Carrasco, M. (2009). Estudio "El cambio lingüístico en la educación en los últimos 25 años en España". Instituto de la Mujer (Ministerio de Igualdad), Madrid, España. Recuperado de: https://www.inmujeres.gob.es/areasTematicas/estudios/serieEstudios/docs/cambioLinguisti coEducacion.pdf 
Divulgatio. Perfiles académicos de posgrado, Vol. 6, Número 16, 2021,47-77 https://doi.org/10.48160/25913530di16.195

Viá Ampuero, J. (2008). Sexismo en el lenguaje científico. Revista sexología y sociedad, 14(39).

Recuperado

de:

http://revsexologiaysociedad.sld.cu/index.php/sexologiaysociedad/article/view/363

Winfield, Reyes A. M. Jiménez Galán, Y. I. Topete Barrera, C. (2017). Representaciones mentales y sociales en la equidad de género. Revista de estudios de género La ventana, 45 , 186-210. ISSN 1405-9436/E-ISSN 2448-7724. Recuperado de: http://www.scielo.org.mx/pdf/laven/v5n45/1405-9436-laven-5-45-00186.pdf. 